Recebido: 04/03/2018

Aprovado: 01/05/2018

\title{
A cooperativa sem lucros de Pedro Ferreira da Silva
}

\author{
Cláudia Tolentino Gonçalves Felipe ${ }^{1}$
}

\section{Resenha de SILVA, Pedro Ferreira da. Cooperativa sem lucros: uma experiência anarquista dentro da sociedade capitalista. São Paulo: Editora Entremares, 2017.}

O título do livro de Pedro Ferreira da Silva pode parecer equivocado: como conceber a existência de uma cooperativa sem finalidades lucrativas? O subtítulo, no entanto, desfaz o equívoco ao precisar o conteúdo da obra: uma experiência anarquista no interior da sociedade capitalista. É no mínimo intrigante a possibilidade de coexistência entre capitalismo e anarquismo, especialmente para quem encara a experiência libertária de forma banal e preconceituosa. Resenhar Cooperativa sem lucros, portanto, mostra-se uma tarefa necessária por duas razões: poderia apontar os nexos entre cooperativismo e anarquia e ajudar-nos a entender o que motivou a republicação de um livro anarquista de 1958 quase sessenta anos depois.

Perseguido pelo governo salazarista, o anarco-sindicalista português Pedro Ferreira da Silva refugiou-se na França em 1926 e, logo em seguida, mudou-se para o

\footnotetext{
${ }^{1}$ Doutoranda em História pela Universidade Estadual de Campinas. claudiatolentino.ufu@gmail.com
} 
Brasil. Em Portugal, ele foi um dos responsáveis pela publicação do semanário $A$ Comuna, editado na cidade do Porto. Convém mencionar que é o mesmo periódico do qual participava o militante anarquista português Roberto das Neves, antes de sua vinda para o Brasil no início dos anos 1940. No Brasil, Pedro Ferreira associou-se aos anarquistas cariocas e paulistas e, ao final da ditadura varguista, começou a participar efetivamente do periódico Ação Direta (1946-1959), publicado no Rio de Janeiro. Aproveitou o espaço que lhe foi destinado para escrever textos críticos sobre o salazarismo, o sindicalismo e o cooperativismo.

Apesar de desempenhar a função de contador, Pedro Ferreira dedicou-se ao jornalismo e escreveu poemas e livros nas áreas de literatura, crítica social e economia. Dentre suas principais obras, destacam-se: Eu creio na Humanidade (1949); Três enganos sociais: férias, previdência e lucro (1953); Cooperativa sem lucros: uma experiência anarquista dentro da sociedade capitalista (1958). Interessa-nos, particularmente, a última obra mencionada, que edifica um projeto revolucionário cujo veículo seria a cooperativa, entendida como uma arma de luta contra a exploração capitalista e como um caminho para a construção de uma sociedade libertária. Para tanto, o autor reuniu uma série de discussões realizadas no Ação Direta entre os anos de 1947 a 1958.

A linguagem adotada no livro é acessível, abrindo mão das figuras de linguagem desfiladas em outros textos de sua autoria, como em Eu creio na humanidade. A disposição de seus artigos assume claramente ares de “projeto”, uma vez que instrui sobre o funcionamento do que seria uma sociedade libertária estruturada por cooperativas sem lucros. Convém mencionar que o autor acredita que a anarquia não se desenvolveria de imediato, carecendo de estratégias intermediárias que pudessem educar os homens, tornando os princípios libertários atrativos e cativantes. A questão a se perguntar é: de que maneira a cooperativa atenderia esse propósito?

Não nos parece conveniente retomar minuciosamente as particularidades de cada um dos 32 artigos do livro escritos pelo autor, mas esboçar a ideia geral que confere ares de unidade ao conjunto. O cooperativismo pensado por Pedro Ferreira remete a uma experiência anárquica dentro da sociedade capitalista e dependeria da iniciativa do indivíduo e de seu esforço associativo. No entanto, o sistema cooperativo corrente deveria passar por mudanças significativas, para se ver livre dos vícios capitalistas. A princípio, o autor declara que não acredita na violência e retoma o conceito de ação direta, definido como ato de perseguir uma finalidade trilhando "caminhos iluminados, pelos meios 
limpos, isentos de colaboração suspeita” (p. 17). As cooperativas seriam uma alternativa intermediária, contanto que se livrasse do lucro e se baseasse em preços justos e acessíveis.

Pedro Ferreira insiste na necessidade de uma cooperação ampliada, multiplicada, que eliminaria a especulação, os salários e concentrar-se-ia no benefício dos consumidores. Note-se que, sem se confundir com a anarquia, o cooperativismo reproduz alguns de seus postulados, já que efetua "a melhoria econômica da classe proletária, a assimilação social e o enfraquecimento dos preconceitos de classe” (p. 27). O autor ressalta a necessidade de a sociedade se livrar dos “intermediários”, dos comerciantes que lucram às custas do consumidor: são eles que, "na indústria como no comércio, o cooperativismo combate, dispensa e destrói” (p. 31). Parece-nos que uma das lutas mais recorrentes nos escritos de Pedro Ferreira é direcionada contra a ideia de o salário ser a finalidade última do trabalhador, e não a produção. Afinal, ele "é um elemento econômico decorrente do trabalho e não um objetivo a conquistar por meio do trabalho” (p. 35). Por outras palavras, se a intenção do trabalho industrializado é o lucro, no caso do trabalho cooperativista, o intuito é a produção. O problema, portanto, é associado à sociedade, pensada como “edifício formado de material ruim”. Uma vez que “matéria ruim não pode fazer edifício bom”, é preciso transformá-la, mas de forma não abrupta, já que a retirada do homem de um edifício ruim e sua introdução num edifício bom não mudaria, de imediato, o próprio homem.

O autor pensa o cooperativismo como estágio necessário para a reformulação do "processo mental” capaz de "fazer com que o homem crie, em volta de si, o ambiente anarquista” (p. 46). Através dele, seria possível desenvolver um "espírito associativo”, a solidariedade e a ajuda mútua. Trata-se de uma “arma revolucionária”, imunizada contra “o contágio da cobiça”, mas que, inicialmente, estaria associada ao capital: só com o tempo o cordão umbilical seria rompido. Para sua administração, seria necessário um “fundo social”, que reuniria um montante indispensável para garantir as instalações, móveis, imóveis etc. Quanto maior fosse a participação, mais eficaz se tornaria a cooperativa. Além do fundo social, haveria um fundo de manutenção e desenvolvimento, para ampliação das operações sociais através de materiais que permitissem sua administração. Não há lugar para os juros. O autor afirma que “o sonho pode estar dentro de nós, mas em torno de nós há a realidade e nela se movem nossas vidas, nela se animam os nossos gestos e se realizam as nossas obras” (p. 73). É por essa razão que seria preciso 
reter um excedente quando da definição dos preços dos produtos e de sua distribuição, para “cobrir possíveis erros de cálculo, desgastes ou perecimentos imprevistos de mercadorias” (p. 74). Pedro Ferreira afirma que a cooperativa não pretende conferir lucro a seus associados, pois não alimenta finalidades mercantilistas. Isso não exclui, no entanto, “a margem necessária ao funcionamento da organização e convenientes reservas” (p. 75).

De um lado, o autor pensa as cooperativas de produção, que tentam conferir aos operários a possibilidade de “trabalhar por sua conta”, sem submeter-se à exploração patronal. As cooperativas de consumo, por sua vez, tendem à universalidade, já que buscam contemplar os consumidores de forma geral. Sendo assim, elas têm o mérito não apenas de eliminar o “intermediário no comércio improdutivo” (p. 100), mas também de aproximar os consumidores de diversas classes, "num movimento comum de defesa econômica, que por sua vez lhes há de inspirar outras formas de cooperação social” (p. 100). Há, portanto, um efeito pedagógico a subsidiar as cooperativas, como o autor admite na passagem abaixo:

O cooperativismo é, pois, um sistema econômico-social de função altamente educativa, e como tal merece maior atenção dos anarquistas, que não o sejam apenas de modo passivamente platônico ou furiosamente arrasador. A ação das cooperativas sem lucros, no terreno industrial ou nas redes distribuidoras dos produtos, leva à emancipação do trabalhador e ao fim do parasitismo comercial; faz converter maior número de braços às tarefas produtivas e semeia o espírito de ajuda, a união e o entendimento comum. Na sua prática, isenta de egoísmo, pode alimentar-se largamente o ideal anarquista e exercitar-se com progressivo êxito mais de um preceito da sociedade livre (pp. 100-101).

Interessa-nos, por agora, retomar a noção de intercooperativismo, que ajuda a compreender a diferença entre liberdade e arbítrio. A liberdade das cooperativas não implica ausência de obrigações que elas devem manter entre si. O homem é livre, mas seu arbítrio "tem de obedecer ao interesse comum” (p. 107). Para Pedro Ferreira, o homem apresenta tendências e impulsos naturais que o levam à sociabilidade, ou seja, há uma “necessidade de cooperação":

Firmada a mentalidade cooperativista, cada sociedade incorporará esse espírito e passará a representa-lo em relação às sociedades congêneres. Então se estabelecerá o ponto de partida para o intercooperativismo, ou seja, a cooperação entre as sociedades, segundo sua natureza, espécie de atividade ou região onde se desenvolve a influência de seu funcionamento (p. 108).

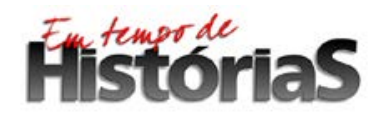

(PPGHIS/UnB) No. 33, Brasília, Ago - Dez 2018 ISSN 2316-1191 
Criar-se-á, portanto, “federações de cooperativas”, não para circunscrever a liberdade de cada uma delas, mas para atribuir-lhes a mesma liberdade conferida aos indivíduos. Eis porque a cooperativa pode ser encarada como um instrumento de preparo psicológico e prático e como uma etapa que conduziria à sociedade libertária. No terreno econômico, ela possibilitaria preços mais baixos; no âmbito educacional, ensinaria normas de respeito ao interesse coletivo e combateria a guerra dos preços e a concorrência capitalista; no domínio da moral, incitaria o respeito pelo semelhante; em termos sociais, incentivaria troca de ideias e projetos de aperfeiçoamento comuns, alimentando as relações humanas; já no que se refere ao âmbito profissional, estimularia a técnica e o aperfeiçoamento pessoal, e não a intensificação do volume de trabalho.

Não poderia faltar o incentivo à arte: uma vez vencido o sistema do patronato, a arte poderia ser valorizada não a partir de seus rendimentos financeiros, mas como veículo de estudo e de promoção da cultura. Poder-se-ia estruturar uma cooperativa artística, com programas independentes dos quais participariam artistas e o público.

Por fim, Pedro Ferreira trata da família, uma "comuna dentro da sociedade que condena o comunismo” (p. 123). Ele a encara como um “núcleo social”, como “ponto de partida da associação humana” (p. 127). A família, portanto, seria uma “cooperativa isolada”, que poderia deixar de sê-lo caso se unisse a outras famílias em associações cooperativas. É o que, posteriormente, daria ensejo à “policooperativa”:

\begin{abstract}
A policooperativa é o organismo social completo. É o indivíduo na constituição da sociedade. Dentro dela estão as peças todas indispensáveis à satisfação das necessidades sociais. Se a cooperativa geral compreender seções de todas as atividades humanas, ou pelo menos de todas as atividades necessárias aos indivíduos que a compõem, é naturalmente muito mais fácil a federação das cooperativas e o intercâmbio de suas ações, conforme as conveniências não nacionais, mas regionais (p. 134).
\end{abstract}

Como se pode ver, o livro de Pedro Ferreira apresenta um encadeamento lógico ao sugerir a cooperativa como uma ferramenta eficaz no combate ao lucro e ao comércio, como estágio necessário à consecução da anarquia. No entanto, é preciso problematizar o lugar que essa obra poderia ocupar no atual cenário histórico a ponto de ter sido reeditada em julho de 2017. Seria uma indicação da fragilidade das cooperativas do século XXI? Uma forma de sugerir a necessidade de cooperação e apoio mútuo na atualidade?

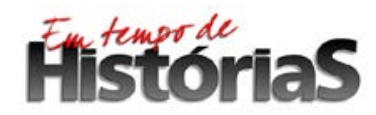


Uma tentativa de inspirar o leitor, convencendo-o da necessidade de se pensar alternativas que contrariem a modernidade líquida? A tomar pelo critério da verossimilhança, essas hipóteses parecem válidas, o que torna louvável a iniciativa da editora Entremares e imperativa a leitura o livro, que combate o individualismo pós-moderno com palavras libertárias de um autor que, há mais de 50 anos, fez da escrita um instrumento contra o egoísmo. Será possível que continua eficaz? Há somente um meio de descobrir: boa leitura! 